\title{
Behavioral responses of free-ranging blue crabs to episodic hypoxia. II. Feeding
}

\author{
Geoffrey W. Bell*, David B. Eggleston, Thomas G. Wolcott \\ North Carolina State University, Department of Marine, Earth, and Atmospheric Sciences, Raleigh, \\ North Carolina 27695-8208, USA
}

\begin{abstract}
Episodic hypoxic events in estuaries can alter the trophic dynamics of important benthic predators. During hypoxic upwelling events mobile predators may reduce their feeding activity as they migrate to relatively shallower, oxygenated water, and may reinvade deep-water habitats during relaxation of hypoxia to exploit vulnerable infaunal prey (e.g. clams and polychaete worms) that have reduced their burial depth in response to hypoxia. We used biotelemetry techniques with concurrent measurements of dissolved oxygen (DO) to monitor the feeding and movement responses of free-ranging blue crabs Callinectes sapidus to episodic hypoxic upwelling and subsequent relaxation events within the Neuse River Estuary (NRE), North Carolina, USA. Although telemetered crabs fed in hypoxic water with DO concentrations as low as $1.01 \mathrm{mg} \mathrm{l}^{-1}$, percent feeding occurrence declined slightly when crabs were exposed to mild ( $\mathrm{DO}=2-4 \mathrm{mg} \mathrm{l}^{-1}$ ) and severe hypoxia $\left(\mathrm{DO}<2 \mathrm{mg} \mathrm{l}^{-1}\right.$ ), relative to normoxic concentrations ( $\mathrm{DO}>4 \mathrm{mg} \mathrm{l}^{-1}$ ). Crabs reduced the proportion of time spent feeding during hypoxic upwelling conditions except for the most severe events when DO dropped rapidly from normoxia to severe hypoxia. The proportion of time crabs spent feeding did not increase and crabs did not reinvade deeper water habitats during relaxation events, as was hypothesized. These results are somewhat inconsistent with previous studies and we suggest that crabs may have fed on prey other than benthic infauna, or that upwelling events may not have lasted long enough to cause infauna to migrate close enough to the sediment surface to be vulnerable to predation by blue crabs. Our study highlights the importance of examining the complex interaction between the hydrodynamics of episodic events and various behaviors (e.g. feeding and movement) when trying to understand the impact of these events on estuarine trophic dynamics.
\end{abstract}

KEY WORDS: Trophic dynamics · Hypoxia · Feeding · Biotelemetry · Blue crab · Callinectes sapidus Predator-prey interactions $\cdot$ Upwelling $\cdot$ Neuse River Estuary $\cdot$ Estuary

\section{INTRODUCTION}

In recent years the spatial extent and severity of seasonal hypoxia within coastal estuaries has increased due to anthropogenic eutrophication from extensive coastal development (Officer et al. 1984, Cooper \& Brush 1993, Diaz \& Rosenberg 1995). The deeper regions of estuaries are the most severely impacted by low dissolved oxygen (DO) concentrations because hypoxic ( $\mathrm{DO}<2 \mathrm{mg} \mathrm{l}^{-1}$ ) and anoxic ( $\mathrm{DO}=0 \mathrm{mg} \mathrm{l}^{-1}$ ) bottom water can persist in these areas for much of the summer (Officer et al. 1984, Stanley \& Nixon 1992, Luettich et al. 2000). Hypoxia and anoxia in the deep channels of estuaries cause severe declines in the biomass of macrobenthic invertebrates that are important prey for higher trophic level organisms (Buzzelli et al. 2002). Therefore, low DO and insufficient food resources in these deep regions may restrict mobile organisms to nearshore habitats where DO concentrations are relatively high (Eby \& Crowder 2002). Hypoxic bottom water, however, is spatially and temporally dynamic in many estuaries because wind and tidal forcing mechanisms cause hypoxic bottom water to upwell from deep basins into shallower nearshore habitats (Breitburg 1990, Sanford et al. 1990, Pihl et al. 1991, Diaz et al. 1992, Luettich et al. 2000). These 
episodic hypoxic upwelling events can alter estuarine trophic dynamics (Pihl et al. 1992, Breitburg et al. 1994, Taylor \& Eggleston 2000); however, the impact of these events on the interactions between mobile benthic predators and their infaunal prey are still poorly understood.

The physiological and behavioral response of estuarine predators and prey to low DO can lead to either increased or decreased prey capture (Breitburg et al. 1994). During upwelling events benthic fish and crab predators, such as spot Leistomus xanthurus, Atlantic croaker Micropogonia undulatus, and blue crab Callinectes sapidus avoid hypoxia and presumably migrate from hypoxic deep water to shallower habitats where DO concentrations are relatively high (Pihl et al. 1991). Benthic infauna (e.g. clams and polychaete worms) that are important prey for spot, croaker, and blue crabs (Hines et al. 1990) vertically migrate close to the sediment surface during exposure to hypoxia (Diaz \& Rosenberg 1995, Taylor \& Eggleston 2000, Tallqvist 2001). Gut content analysis suggests that after hypoxic water recedes back to the deeper basins of the estuary (i.e. relaxation events) some predators (e.g. spot and croaker) may reinvade deeper water habitats to feed on additional benthic prey species (e.g. deep burrowing polychaetes and anemones) and larger prey that reduce their burial depth in response to hypoxia (Pihl et al. 1992).

A recent series of laboratory studies suggested that episodic hypoxia may also alter predator-prey dynamics between blue crabs and their infaunal clam prey. For example, blue crabs switched from an inversely density dependent Type II functional response during normoxic conditions to a density independent Type I functional response during simulated hypoxic upwelling events (Taylor \& Eggleston 2000). The switch to a Type I response provided a partial predation refuge for clams at low densities during upwelling events because exposure to mild hypoxia led to reduced blue crab foraging activity. Conversely, blue crabs exhibited a Type II functional response during simulated relaxation events in the laboratory, in which there was no predation refuge at low prey densities, and crabs consumed all prey within a patch resulting in local prey extinction (Taylor \& Eggleston 2000). The increased vulnerability of clams at low density was attributed to a decrease in sediment burial depth and increase in siphon extension for clams exposed to hypoxia, which resulted in the loss of their depth refuge (Taylor \& Eggleston 2000). Thus, hypoxic events can lead to either increased or decreased prey capture, thereby affecting a predator's functional response (Taylor \& Eggleston 2000), as well as food web dynamics within marine and estuarine communities (Breitburg et al. 1994).
Although these previous laboratory studies have identified important behavioral mechanisms that may alter the trophic dynamics between a key estuarine predator and its infaunal prey, there is no information on the feeding response of free-ranging mobile predators to episodic hypoxic events. Tracking the feeding response of free-ranging animals to the spatial and temporal dynamics of hypoxia is essential for assessing the applicability of laboratory results to the natural environment, and for modeling the population and trophic-level consequences of hypoxia and anoxia.

In this study, we used biotelemetry with concurrent hydrographic measurements to track the feeding response of free-ranging blue crabs to temporal variation in hypoxia within the Neuse River Estuary (NRE), North Carolina, USA. We also describe diel patterns of crab feeding behavior. Our study tested 2 general hypotheses concerning blue crab feeding response to hypoxia: We expected free-ranging crabs to decrease the proportion of time spent feeding when DO dropped to hypoxia (i.e. upwelling), and increase the proportion of time spent feeding when DO increased from hypoxia (i.e. relaxation).

\section{MATERIALS AND METHODS}

Study site. Our study site was located along the northern shore of the NRE, just upriver of Minnesott Beach, and near the mouth of Beards Creek (see Fig. 1 in Bell et al. 2003, this issue). Seasonal bottom water hypoxia during summer months in the NRE results from intense vertical stratification of the water column. Hypoxic water can cover 20 to $40 \%$ of the bottom in the deepest upstream portions of the NRE (Eby 2001), and is thought to be an important cause of the near-complete mortality of infaunal clams Macoma sp. in some areas (Buzzelli et al. 2002). Clams are an important benthic prey for many demersal fish and crustaceans (Hines et al. 1990). Therefore, a combination of low DO and reduced food availability within the deepest sections of the NRE may restrict fish and crabs to relatively shallow nearshore habitats (Eby 2001, McClellan 2001, Eby \& Crowder 2002). Changes in wind direction, however, can cause hypoxic bottom water from the deepest parts of the river to rapidly upwell into the nearshore habitats of the NRE (Luettich et al. 2000). Winds from the southwest cause hypoxic upwelling along the southern shore whereas northeast winds cause hypoxic upwelling on the northern shore at our study site (Luettich et al. 2000). Upwelled hypoxic water may remain in nearshore habitats from hours to days until it recedes back to the deep basins of the river (relaxation of hypoxia) (Luettich et al. 2000, Bell et al. 2003). 
Thus, the episodic hypoxic upwelling events in the NRE are ideal for measuring the behavioral response of mobile animals, such as blue crabs, to the spatial and temporal dynamics of hypoxia.

The study site was divided into 3 depth strata (Fig. 1) based on the occurrence of hypoxia within each stratum. The deep stratum (depth range $=3.0$ to $4.6 \mathrm{~m} ; \bar{x}=$ $3.7 \mathrm{~m}$ ) was always hypoxic if hypoxia was present within the study site, the mid-depth stratum (depth range $=1.7$ to $3.0 \mathrm{~m} ; \bar{X}=2.2 \mathrm{~m}$ ) only experienced hypoxia during upwelling events, and the shallow stratum (depth range $=0.9$ to $1.7 \mathrm{~m} ; \bar{x}=1.3 \mathrm{~m}$ ) was rarely hypoxic. The study area was approximately $2.15 \mathrm{~km}^{2}$ and summer salinities ranged from 10 to $17 \mathrm{psu}$.

Transmitter design and tagging. We used a multichannel biotelemetry system to monitor movement and feeding behavior of individual free-ranging blue crabs. The transmitters were modified slightly from previous designs that successfully observed foraging behavior of free-ranging blue crabs in estuarine systems (Wolcott \& Hines 1989, Clark et al. 1999a,b, 2000). The electronic circuitry of the transmitter was packaged in shrink tubing which was molded to conform to the dorsal surface of the carapace (to reduce drag), and filled with mineral oil to couple sound between the transducer and water. The packaged transmitter was bonded to the dorsal surface of the carapace using cyanoacrylate glue and fastened with metal wire to the lateral spines (see Fig. 2 in Clark et al. 1999a). Transmitters were $80 \mathrm{~mm}$ long, $25 \mathrm{~mm}$ wide, and weighed approximately $24 \mathrm{~g}$ in air.

Transmitters were equipped with external wires and electrodes that were fastened to the carapace to monitor feeding and agonistic behaviors (results on agonistic behavior are not reported in this paper). Transmitters recorded consumption rates of free-ranging crabs by measuring biopotentials of the mandible adductor muscle with 2 stainless steel electrodes that were inserted through the exoskeleton and into the muscle; activity of this muscle is a definitive indicator of feeding (Wolcott \& Hines 1989). The insertion site on the carapace was first cleaned with a paper towel to dry the area and remove algal growth. We then drilled 2 small holes (diameter $\sim 0.5 \mathrm{~mm}$ ) partially through the exoskeleton at the origin of the mandible adductor muscle where the electrodes were inserted into the muscle. The insertion site was then covered with cyanoacrylate glue and a rubber membrane (dental dam) to hold the wires in place and waterproof the site. Each crab was held for 12 to $24 \mathrm{~h}$ prior to release to ensure that the transmitter was functioning properly and that the crab had not been injured during the tagging process (approximately $1 \mathrm{~h}$ of preparation time). Transmitters of similar design did not interfere with common blue crab behaviors including feeding, ago- nism, and mating (Nye 1989, Wolcott \& Hines 1989, 1990, Clark et al. 1999a, 2000).

Tracking movement and feeding. A total of 14 adult, intermolt crabs (carapace width [CW] range $=135$ to $175 \mathrm{~mm}$ ) were collected with crab pots from the study site and tracked from July through September of 2001 and 2002. We used male crabs for this study because females of similar size migrate down river during this period to spawn and hatch larvae (Judy \& Dudley 1970). Adult blue crab migration patterns are primarily downriver in this area (E. G. Johnson, North Carolina State University, pers. comm.); therefore, we released telemetered crabs at upriver locations within the study site (near the mouth of Beards Creek) to reduce the likelihood of crabs leaving the study area before tracking was completed. Release locations varied with respect to time of day (day, twilight, and night), DO concentration ( 3 to $8 \mathrm{mg} \mathrm{l}^{-1}$ ) and depth (1 to $4 \mathrm{~m}$ ). Crabs were tracked continuously for 72 to $96 \mathrm{~h}$ with occasional interruptions due to severe weather or boat problems. Tracking was terminated early $(<42 \mathrm{~h}$ ) for 4 crabs because either the transmitter failed, the crab died, the crab was mating (consequently rarely moving or feeding), or the crab had not moved or fed in over $12 \mathrm{~h}$.

We used a Sonotronics USR-5W ultrasonic receiver and unidirectional hydrophone to track individual crabs from a $6 \mathrm{~m}$ boat. Crabs were relocated every 40 to $60 \mathrm{~min}$, or earlier if it appeared that they might move out of listening range. A crab's position was recorded by marking the boat's location with a differential global positioning system (DGPS). There was some minor error in our estimate of the true position of a crab due to inaccuracy of tracking equipment (noise interference from waves and boat propellers) and imprecision of the DGPS; however, the recorded position was always within $6 \mathrm{~m}$ of the true position (Bell et al. 2003). The time interval between successive relocations was used to record feeding behavior data sent by the transmitter. Transmitters recorded individual bites, stored this information in 10 min intervals, and used binary encoded pulses of $\sim 75 \mathrm{kHz}$ to transmit the feeding data to the receiver. Feeding rate was recorded as the number of bites taken in 10 min intervals; however, we report feeding rate as bites per min.

Hydrographic measurements and DO scenarios. As soon as a crab was relocated, we measured 'initial' surface and bottom water temperature, DO, and salinity with a YSI Model 85 handheld instrument, depth (to the nearest $0.3 \mathrm{~m}$ ) with the boat's depth finder, and recorded the date and time using the boat's DGPS. Additionally, 'final' bottom hydrographic measurements were recorded prior to moving to the next relocation point so that changes in DO at each location could be calculated by subtracting 'final' from 'initial' measurements. 
Changes in DO at each relocation point were assigned to 1 of 7 DO scenarios. Three of the scenarios were assumed to represent a variety of DO changes that blue crabs would encounter during hypoxic upwelling events. DO could: (1) decrease from normoxia $\left(>4 \mathrm{mg} \mathrm{l}^{-1}\right.$ ) to mild hypoxia (2 to $4 \mathrm{mg} \mathrm{l}^{-1}$ ), (2) decrease from mild hypoxia to severe hypoxia $\left(<2 \mathrm{mg} \mathrm{l}^{-1}\right)$, or (3) decrease from normoxia to severe hypoxia (the most extreme drop in DO). Three other DO scenarios were assumed to approximate changes in DO during relaxation events. DO could: (1) increase from severe hypoxia to mild hypoxia, (2) increase from severe hypoxia to normoxia, or (3) increase from mild hypoxia to normoxia. The last DO scenario was assumed to represent a 'control' treatment that the 6 other scenarios could be compared with statistically. DO could increase or decrease for this scenario; however, both 'initial' and 'final' DO concentrations were normoxic. Two designations for hypoxia (mild and severe) were chosen for our analyses because it is presently unclear what DO concentrations are considered hypoxic by blue crabs. We used $4 \mathrm{mg} \mathrm{l}^{-1}$ as the cut-off between normoxia and mild hypoxia because laboratory results suggest that blue crabs begin to alter their behavior and physiology below this DO concentration (Batterton \& Cameron 1978, Das \& Stickle 1994). We chose $2 \mathrm{mg} \mathrm{l}^{-1}$ as the cut-off between mild and severe hypoxia because below this DO concentration anaerobic respiration is activated and survival is low (Das \& Stickle 1993, Mangum 1997).

Statistical analyses. Feeding response to hypoxia: To assess blue crab feeding response to hypoxic upwelling and relaxation events we examined the proportion of time spent feeding during all 7 DO scenarios. First, consumption rates were calculated for each relocation by averaging the number of bites across all 10 min time intervals that corresponded to a period of no more than $60 \mathrm{~min}$ after the initial relocation time. Each relocation was then classified as either nonfeeding or feeding (mean feeding rate $>0.3$ bites $\mathrm{min}^{-1}$; Wolcott \& Hines 1989), and assigned to 1 of the 7 DO scenarios. For each crab, we calculated the percent feeding occurrence (i.e. percent of relocations where feeding occurred) during all 7 DO scenarios. These values ( 1 per crab) were used as replicates in paired $t$-tests for testing the following hypotheses. We hypothesized that during the 3 DO scenarios where DO dropped to hypoxia (i.e. hypoxic upwelling events), percent feeding occurrence would decrease relative to the normoxic control treatment. Conversely, during DO scenarios where DO increased from hypoxia (i.e. relaxation events), we hypothesized that percent feeding occurrence would increase relative to the control treatment. Many crabs did not experience all 7 DO scenarios; therefore, sample sizes varied from 5 to 8 among tests. Furthermore, only $1 \mathrm{crab}$ experienced an increase in DO from severe hypoxia to normoxia ( $\mathrm{n}=1$ ); thus, results for this scenario are not reported.

Diel feeding patterns: To determine if free-ranging crabs displayed diel patterns in feeding behavior, we classified each behavioral observation (number of bites recorded within each $10 \mathrm{~min}$ interval) according to time of day: day ( $1 \mathrm{~h}$ after sunrise to $1 \mathrm{~h}$ before sunset), night ( $1 \mathrm{~h}$ after sunset to $1 \mathrm{~h}$ before sunrise), and twilight ( $1 \mathrm{~h}$ before and after sunrise and sunset). We calculated the proportion of time spent feeding (i.e. proportion of $10 \mathrm{~min}$ time intervals classified as feeding), and the mean consumption rate (feeding observations only) during each diel period for each crab. We used paired-sample $t$-tests to determine if either feeding response differed significantly among diel periods.

The assumption of normality was tested using a Kolmogorov-Smirnov (K-S) test. In some cases non-normal data were transformed using an arcsine transformation (Zar 1984). Spatial and temporal autocorrelation were controlled for by reducing the numerous feeding observations along each crab's telemetry track to a single replicate in each $t$-test, thus, replicates were independent.

\section{RESULTS}

\section{General and diel feeding patterns}

Crabs usually fed continuously for periods of 20 to $40 \mathrm{~min}$; these feeding bouts could occasionally persist for up to $2 \mathrm{~h}$. The duration of nonfeeding periods was highly variable, averaging approximately $1 \mathrm{~h}$ and ranging from $10 \mathrm{~min}$ to $26 \mathrm{~h}$. Consumption rates were highly variable among crabs $(\bar{x}=3.79 \pm 0.39$ bites $\min ^{-1}$; range $=1.69$ to 7.10 bites $\min ^{-1}$; Table 1 ). Within 10 min time intervals, the number of bites rarely reached or exceeded the capacity of the transmitter's 'bite counter' (255). The proportion of time crabs spent feeding was highly variable. For each crab, the proportion of time spent feeding ranged from 3.4 to $50 \%$ and averaged $20 \%$ across all crabs (Table 1). Crabs fed more frequently in shallow areas relative to mid- and deep depths. For example, crabs spent an average of $23 \%$ of their time feeding in shallow areas as compared to 16 and $10 \%$ in mid- and deep depths, respectively.

Telemetered crabs did not exhibit much difference in feeding behavior among diel periods. Crabs fed approximately $20 \%$ of the time during all 3 diel periods (day: $19.96+2.91 \%$; night: $20.45+5.01 \%$; twilight: $23.26+5.83 \%$ ) (Fig. 1a). Percent feeding occurrence did not significantly differ between diel periods (paired $t$-tests: day vs twilight: $\mathrm{df}=13, t=-0.51, \mathrm{p}=0.62$; 
Table 1. Callinectes sapidus. Tracking information for individual crabs including release date, carapace width (CW), and duration of tracking events. Percent feeding occurrence, and consumption rate: mean no. feeding bites min ${ }^{-1}$ ). Averages of percent feeding occurrence, and feeding rate across crabs are also provided. Exact carapace width measurements for 'Dale Earnhardt' and 'George Dickel' were not available, but were approximately the same size as other crabs

\begin{tabular}{|c|c|c|c|c|c|}
\hline $\begin{array}{l}\text { Release date } \\
\text { (m/dd/yy) }\end{array}$ & Crab ID & $\begin{array}{l}\text { CW } \\
(\mathrm{mm})\end{array}$ & $\begin{array}{c}\text { Tracking duration } \\
\text { (h:min) }\end{array}$ & $\begin{array}{l}\text { Percent feeding } \\
\text { occurrence }(\%)\end{array}$ & Consumption rate \\
\hline $7 / 24 / 00$ & Billy Bob & 154 & $69: 11$ & 24.1 & $2.31 \pm 0.23$ \\
\hline $7 / 31 / 00$ & Billy Rae & 149 & $60: 07$ & 26.0 & $4.18 \pm 1.07$ \\
\hline $8 / 07 / 00$ & Joe Bob & 151 & $73: 53$ & 14.4 & $3.22 \pm 0.89$ \\
\hline $8 / 13 / 00$ & Cletus Lee & 138 & $95: 20$ & 3.4 & $2.21 \pm 0.77$ \\
\hline $8 / 24 / 00$ & Clawed & 135 & $85: 41$ & 22.1 & $1.69 \pm 0.26$ \\
\hline $9 / 11 / 00$ & Uncle Jessie & 152 & $95: 55$ & 7.1 & $6.14 \pm 1.23$ \\
\hline $9 / 19 / 00$ & Boss Hog & 140 & $73: 37$ & 11.4 & $4.25 \pm 0.69$ \\
\hline $9 / 24 / 00$ & Jethro & 148 & $71: 37$ & 10.9 & $7.10 \pm 0.86$ \\
\hline $7 / 22 / 01$ & Dale Earnhardt & $\sim 150$ & $67: 22$ & 28.9 & $3.79 \pm 0.54$ \\
\hline 8/08/01 & George Dickel & $\sim 150$ & $30: 21$ & 50.0 & $3.97 \pm 0.67$ \\
\hline 8/11/01 & John Steinbeck & 162 & $42: 32$ & 14.0 & $3.64 \pm 0.93$ \\
\hline 8/17/01 & Crab Pitt & 175 & 29:09 & 15.2 & $2.46 \pm 0.49$ \\
\hline 9/05/01 & Cooter & 170 & $26: 34$ & 39.1 & $3.94 \pm 0.82$ \\
\hline $9 / 08 / 01$ & Feeds Alot & 159 & $38: 12$ & 15.4 & $4.14 \pm 1.03$ \\
\hline Averages: & & & & 20.1 & $3.79 \pm 0.39$ \\
\hline
\end{tabular}

day vs night: $\mathrm{df}=13 ; t=-0.11, \mathrm{p}=0.91$; night vs twilight: $\mathrm{df}=13, t=-0.92 ; \mathrm{p}=0.38$ ). Mean consumption rate was lower for twilight $\bar{x}=2.54 \pm 0.51$ bites $\min ^{-1}$ ) than for day $\bar{x}=4.19 \pm 0.56$ bites $\mathrm{min}^{-1}$ ) or night $\bar{x}=3.75 \pm 0.73$ bites $\mathrm{min}^{-1}$ ) and significantly different than both day and night (twilight vs day: $\mathrm{df}=13$; $t=$ $2.26 ; \mathrm{p}=0.04$; twilight vs night: $\mathrm{df}=13 ; t=2.15 ; \mathrm{p}=$ 0.05) (Fig. 1b). Therefore, with the exception of a reduced occurrence of feeding during twilight, crabs did not show a diel pattern in feeding behavior.

\section{Feeding response to hypoxia}

Although some telemetered crabs fed in hypoxic water where DO concentrations were as low as $1.01 \mathrm{mg} \mathrm{DO}^{-1}$, they generally exhibited a negative feeding response to mild and severe hypoxia. For example, percent feeding occurrence was less for crabs exposed to mild and severe hypoxia (15.31 and $26.88 \%$, respectively) than to normoxia $(33.14 \%)$. Moreover, consumption rates were slightly reduced during exposure to mild or severe hypoxia (2.16 and 2.13 bites $\min ^{-1}$ ), relative to normoxia (2.77 bites $\min ^{-1}$ ). Therefore, crabs fed somewhat less frequently and decreased their consumption rates during exposure to mild and severe hypoxia.

Crab feeding responses to hypoxic upwelling events were generally consistent with our original hypotheses; however, feeding responses to relaxation events were contrary to what was expected. For example, percent feeding occurrence during the 3 upwelling scenarios (normoxia to mild hypoxia: $13.54 \%$; mild hypoxia to se- vere hypoxia: $4.17 \%$; normoxia to severe hypoxia: $25.00 \%$ ) was less than the normoxic control (34.75\%). Percent feeding occurrence was only significantly less
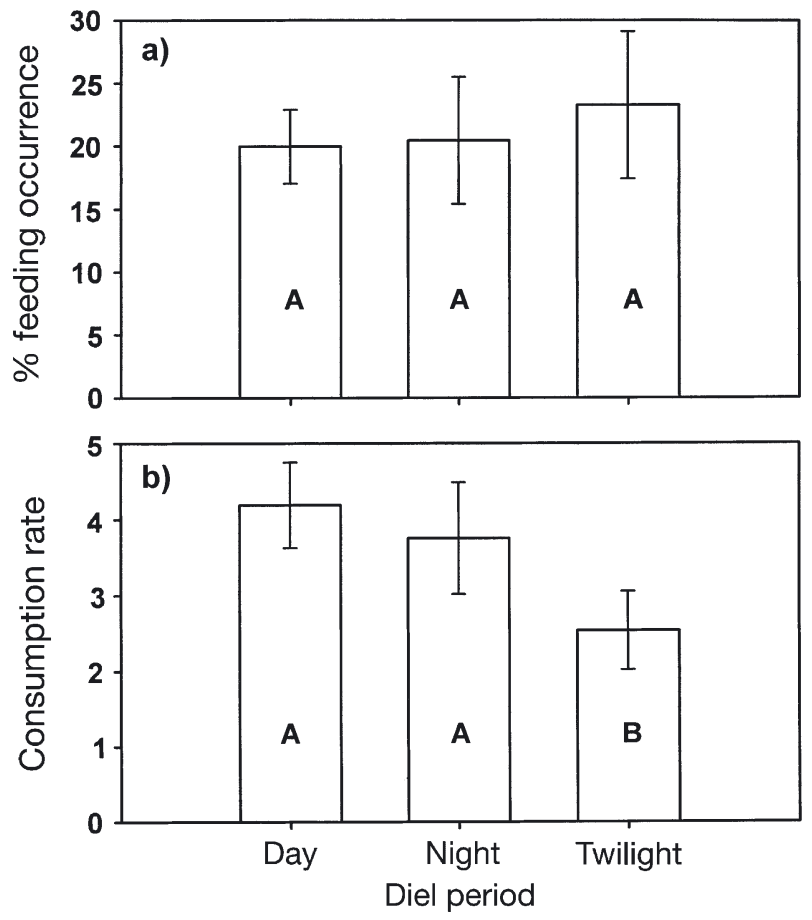

Fig. 1. Callinectes sapidus. Diel patterns in percent feeding occurrence (\% of 10 min time intervals where feeding occurred), and consumption rates (no. bites $\min ^{-1}$ ). Plotted are means of 14 crabs \pm standard errror. Data bars with different letters (e.g. A and B) denote diel periods that had significantly different feeding responses $(2$-sided paired $t$-test, $\mathrm{p}<0.05$ ) 


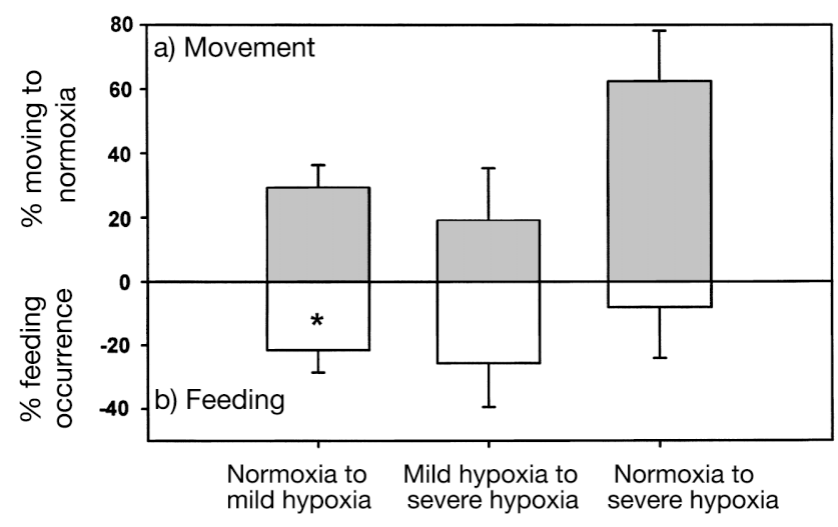

Fig. 2. Callinectes sapidus. Feeding and movement responses of telemetered crabs to the 3 DO scenarios that approximate hypoxic upwelling events. (a) Proportion of times crabs moved to normoxic water (i.e. successfully avoided hypoxia) during each DO scenario (adapted from Bell et al. 2003). (b) Difference in percent feeding occurrence between each DO scenario and the normoxic 'control' treatment (actual values for each scenario are reported in text). Negative values signify decreased feeding relative to the normoxic treatment. *: feeding response that is significantly less than the 'control' treatment $(1$-sided paired $t$-test; $\mathrm{p}<0.05)$

than the normoxic control; however, when DO dropped from normoxia to mild hypoxia (paired $t$-test, $\mathrm{df}=7, t=-1.53, \mathrm{p}=0.009$ ) and marginally nonsignificant when DO dropped from mild hypoxia to severe hypoxia ( $\mathrm{df}=5, t=-1.86, \mathrm{p}=0.06$ ) (Fig. 2b). When DO increased (i.e. relaxation events), percent feeding occurrence did not increase as originally hypothesized. Percent feeding occurrence was less during relaxation scenarios (mild hypoxia to normoxia $\bar{x}=2.08 \%$; severe hypoxia to mild hypoxia $\bar{x}=0.0 \%$ ) than during normoxic control conditions $(34.75 \%)$. Percent feeding occurrence was significantly less than the normoxic control for both relaxation scenarios (mild hypoxia to normoxia: $\mathrm{df}=7, t=-2.0, \mathrm{p}=0.003$; severe hypoxia to mild hypoxia $\mathrm{df}=4, t=-1.65, \mathrm{p}=0.015$ ) (Fig. 3b). Therefore, crabs showed a modest negative feeding response to hypoxic upwelling events and decreased their occurrence of feeding when exposed to hypoxia during relaxation events, which was opposite to our original hypotheses, in which crabs would take advantage of shallow buried prey during relaxation events.

\section{DISCUSSION}

We originally hypothesized that free-ranging crabs would reduce feeding activity during upwelling events as they moved to avoid hypoxic water, and increase feeding activity during relaxation events as they migrated to deeper water to take advantage of infaunal prey that had presumably reduced their burial depth in response to hypoxia. Our results suggest, however, that although free-ranging crabs may reduce feeding activity during relatively mild hypoxic upwelling events, they will continue to feed during the most extreme events when DO drops rapidly from normoxia to severe hypoxia. Moreover, contrary to our original hypotheses, crabs did not increase feeding activity during relaxation events. Integrating both feeding and movement behaviors of our free-ranging crabs, however, may explain our results and help to determine whether these hypoxic events alter estuarine trophic dynamics.

\section{Feeding response to upwelling events}

Of the 2 upwelling scenarios where the decline in DO was less severe (i.e. normoxia to mild hypoxia and mild hypoxia to severe hypoxia), percent feeding occurrence was only significantly less than normoxic conditions when DO decreased from normoxia to mild hypoxia. Some evidence, however, suggests that crabs may have also reduced their feeding activity for the scenario where DO dropped from mild to severe hypoxia. For example, only 1 of 6 crabs fed during this scenario and the $p$-value was marginally nonsignificant $(p=0.06)$. Sample size was relatively small for the

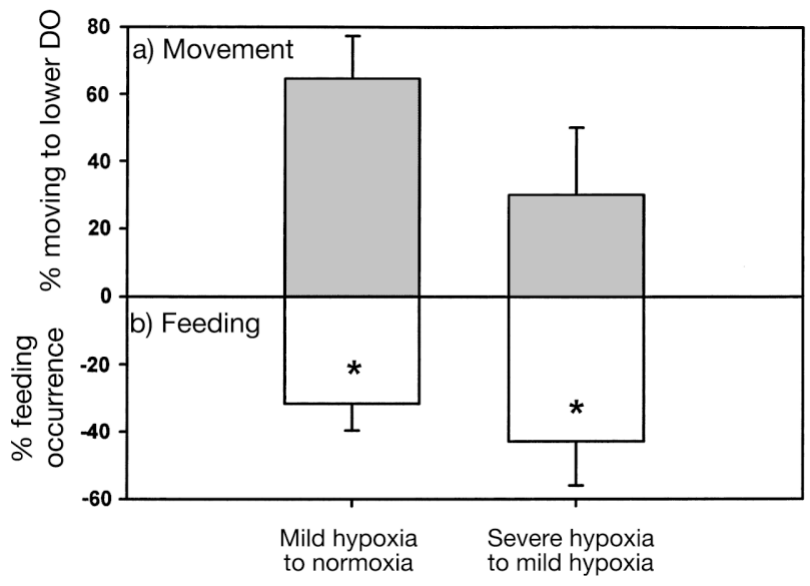

Fig. 3. Callinectes sapidus. Feeding and movement responses of telemetered crabs to the 2 DO scenarios that approximate hypoxic relaxation events. (a) Proportion of times crabs moved to lower DO (i.e. moved to deeper water where they could take advantage of shallow-buried infaunal prey) during each DO scenario (adapted from Bell et al. 2003). (b) Difference in percent feeding occurrence between each DO scenario and the normoxic 'control' treatment (see text actual values for each scenario). Negative values signify decreased feeding relative to the normoxic treatment. *: feeding response that is significantly less than the 'control' treatment $(1$-sided paired $t$-test; $\mathrm{p}<0.05)$ 
mild to severe hypoxia scenario $(\mathrm{n}=6)$, when compared to the other 2 upwelling scenarios $(\mathrm{n}=8)$; thus, we may not have detected a significant difference because of low statistical power. We conclude, therefore, that blue crabs likely reduced their feeding activity during the 2 less severe upwelling scenarios but not during the most severe scenario.

The movement patterns of telemetered crabs differed qualitatively between the 2 less severe upwelling scenarios where crabs reduced feeding activity and the most extreme upwelling scenario where crabs did not reduce their feeding activity. Crabs were largely unsuccessful at avoiding hypoxia during the less severe upwelling scenarios, moving to normoxic water 20 to $30 \%$ of the time (Fig. 2a) (Bell et al. 2003). Conversely, during the most severe upwelling scenario crabs were 2 to 3 times more likely to successfully avoid hypoxia, moving to normoxic water $63 \%$ of the time (Fig. 2a) (Bell et al. 2003). Moreover, the crabs that fed during the most extreme upwelling scenario did so only after successfully moving to normoxic water. This suggests that crabs experiencing less severe drops in DO were largely unsuccessful at avoiding hypoxia, remained within hypoxic water after the drop in DO, and likely reduced their feeding activity because of exposure to hypoxic water. Conversely, crabs that experienced the most extreme drop in DO continued to feed because they were more likely to successfully avoid hypoxia.

The differences in blue crab feeding and movement responses between severe and less severe upwelling scenarios may be due to hydrodynamic differences among events. For example, the rate of change in declining DO is more than twice as fast during the most severe upwelling scenario $\left(4.5 \mathrm{mg} \mathrm{l}^{-1} \mathrm{~h}^{-1}\right)$ compared to the less severe scenarios $\left(1.9 \mathrm{mg} \mathrm{l}^{-1} \mathrm{~h}^{-1}\right)$. Rate of DO change is positively correlated with upwelling current velocities in this region of the NRE (R. Luettich, IMSUNC, pers. comm.), and faster current speeds can enhance the orientation success of blue crabs to chemical cues (Weissburg \& Zimmerfaust 1993). The relationship between the rate of DO change, current speed, and blue crab orientation success suggests that blue crabs may be more successful at avoiding hypoxic water during severe events (i.e. when DO drops rapidly due to faster upwelling current velocities) because of stronger orientation cues than less severe events (Bell et al. 2003). Therefore, blue crabs appear more likely to move to normoxic water and continue to feed during severe upwelling events than less severe events.

\section{Feeding response to relaxation events}

Free-ranging crabs that were exposed to severe hypoxia during relaxation events (i.e. when DO in- creased from severe to mild hypoxia) did not increase feeding activity, as was originally hypothesized. These results are not completely unexpected since blue crabs stop feeding and become quiescent during exposure to severe hypoxia (Lowery \& Tate 1986, Das \& Stickle 1994). Even after re-exposure to normoxia blue crabs take several hours to resume normal feeding and activity patterns (Lowery \& Tate 1986, Das \& Stickle 1994) as they recover from physiological stress associated with exposure to severe hypoxia (Lowery \& Tate 1986). Similarly, our free-ranging crabs did not feed when DO increased from severe to mild hypoxia and were least likely to move to a new location during this scenario. Moreover, crabs moved to lower DO only $30 \%$ of the time when DO increased from severe hypoxia (Fig. 3a) (Bell et al. 2003) which is considerably less than would be expected if crabs reinvaded deeper water habitats to take advantage of shallow-buried infaunal prey. Therefore, crabs trapped in severely hypoxic water prior to relaxation events probably need to recover from physiological stress and are unlikely to move to deeper water and exploit infaunal prey that have reduced their burial depth in response to hypoxia.

Free-ranging crabs that were exposed to mild hypoxia prior to relaxation events also did not increase feeding activity as was originally hypothesized. This result is somewhat inconsistent with laboratory studies where blue crabs took advantage of shallow-buried infaunal clams during simulated hypoxic relaxation events (Taylor \& Eggleston 2000). The changes in DO that Taylor \& Eggleston (2000) used to simulate relaxation events were similar to DO changes our free-ranging crabs experienced during the scenario where DO increased from mild hypoxia to normoxia. Our freeranging crabs, however, did not reinvade deeper water as was expected for this DO scenario. For example, although crabs moved to lower DO $65 \%$ of the time (Fig. 3a), this was not significantly different from a random movement response (Bell et al. 2003). Furthermore, blue crab movements were not directed towards deeper, offshore waters during this DO scenario (Bell et al. 2003). Therefore, even when exposed to mild hypoxia during relaxation events free-ranging crabs did not move to deeper water to exploit vulnerable infaunal prey. This suggests that hypoxic relaxation events may not alter blue crab trophic dynamics within this region of the NRE.

Two alternative hypotheses may help explain the inconsistency between our study and that of Taylor \& Eggleston (2000). First, hypoxic upwelling events within our study site may not have lasted long enough for infaunal prey to significantly reduce their burial depth. Secondly, alternative prey (e.g. fish and other crabs) may be an important source of food for blue crabs in the NRE during the time period of our study. 
Blue crabs in laboratory studies increased consumption rates of clams during simulated relaxation events only after clams had been allowed to vertically migrate in response to hypoxia for $24 \mathrm{~h}$ (Taylor \& Eggleston 2000). Moreover, nearshore habitats in Chesapeake Bay were hypoxic for several days before demersal fish could exploit infaunal prey that had reduced their burial depth in response to hypoxia (Diaz et al. 1992, Pihl et al. 1992). Conversely, hypoxic upwelling events within our study site usually lasted $5 \mathrm{~h}$ and rarely persisted for more than $10 \mathrm{~h}$ (Bell et al. 2003). Therefore, hypoxic upwelling events may not have lasted long enough for infauna to migrate vertically to shallow depths that would make them more susceptible to predation by blue crabs.

Alternatively, benthic infauna may not have been an important part of the adult blue crab diet within our study site. For example, although benthic infauna are a large component of adult blue crab diet in some estuarine systems (Laughlin 1982, Hines et al. 1990), the relative proportion of other prey in blue crab stomachs, such as fish and crabs, can vary spatially and seasonally (Laughlin 1982). Because infaunal prey abundance is lower during late summer (August and September) than early summer (e.g. June and July) (Hines \& Comtois 1985, Hines et al. 1990), and blue crab diets often reflect prey availability (Laughlin 1982), blue crabs may switch to alternative prey, such as fish and crabs, when infaunal prey become limiting. Evidence from our biotelemetry study also suggests that alternative prey may be important to crabs within our study site. For example, our free-ranging crabs consistently fed in areas that were devoid of infaunal prey. Furthermore, preliminary spatial analysis of blue crab consumption rates and infaunal density suggests that free-ranging crab consumption rates were not correlated with in situ infaunal density (author's unpubl. data). This is inconsistent with previous laboratory (Lipcius \& Hines 1986, Mansour \& Lipcius 1991, Eggleston et al. 1992) and field studies (Clark et al. 2000, Seitz \& Lipcius 2001, Seitz et al. 2001). Collectively, these results suggest that blue crabs may rely on alternative sources of prey in the NRE especially during late summer months when infaunal prey availability is limited. If infaunal clams were not a significant source of food for blue crabs this may explain why our free-ranging crabs did not increase their feeding activity during relaxation events.

This study emphasizes the importance of examining the complex interaction between hypoxic upwelling hydrodynamics (e.g. rate of DO change, current velocity, and duration of upwelling events), as well as the movement and feeding responses of free-ranging animals to these events when trying to understand how episodic disturbance events alter estuarine trophic dynamics. Little is known about how variations in the hydrodynamics of hypoxic upwelling and subsequent relaxation events effect the movement and feeding behavior of organisms. This type of information is needed if we are to model and predict the trophic-level consequences of episodic hypoxic events. Lastly, our results demonstrate that hypotheses, generated from laboratory studies, need to be tested in the field using biotelemetry where movement and feeding behaviors can interact to effect estuarine trophic dynamics.

Acknowledgements. We thank the numerous graduate student volunteers and technicians for their hard work during the field season, including: R. Aguilar, C. Bergeron, J. Chaves, G. Dickel XII, A. Drew, L. Etherington, M. Fitchett, E. Johnson, D. Kirkiewiz, H. Major, C. Marquette, H. Preston, N. Reyns, and M. Weiner. We also thank M. Fuentes, J. Hightower, and the anonymous reviewers for their valuable scientific and editorial comments that improved the content of this manuscript. Financial support for this project was provided by grants from the North Carolina Sea Grant Program to D.B.E. and T.G.W. (R/MRD-43), the National Science Foundation (OCE97-34472) to D.B.E., and the Sigma Xi Scientific Research Society to G.B.

\section{LITERATURE CITED}

Batterton CV, Cameron JN (1978) Characteristics of resting ventilation and response to hypoxia, hypercapnia, and emersion in the blue crab Callinectes sapidus (Rathbun). J Exp Zool 203:403-418

Bell GW, Eggleston DE, Wolcott TG (2003) Behavioral responses of free-ranging blue crabs to episodic hypoxia. I. Movement. Mar Ecol Prog Ser 259:215-225

Breitburg DL (1990) Near-shore hypoxia in the Chesapeake Bay: patterns and relationships among physical factors. Estuar Coast Shelf Sci 30:593-609

Breitburg DL, Steinberg ND, DuBeau S, Cooksey C, Houde ED (1994) Effects of low dissolved oxygen on predation on estuarine fish larvae. Mar Ecol Prog Ser 104:235-246

Buzzelli CP, Luettich RA Jr, Powers SP, Peterson CH, McNinch JE, Pinckney JL, Paerl HW (2002) Estimating the spatial extent of bottom-water hypoxia and habitat degradation in a shallow estuary. Mar Ecol Prog Ser 230:103-112

Clark ME, Wolcott TG, Wolcott DL, Hines AH (1999a) Foraging and agonistic activity co-occur in free-ranging blue crabs (Callinectes sapidus): observation of animals by ultrasonic telemetry. J Exp Mar Biol Ecol 233:143-160

Clark ME, Wolcott TG, Wolcott DL, Hines AH (1999b) Intraspecific interference among foraging blue crabs Callinectes sapidus: interactive effects of predator density and prey patch distribution. Mar Ecol Prog Ser 178:69-78

Clark ME, Wolcott TG, Wolcott DL, Hines AH (2000) Foraging behavior of an estuarine predator, the blue crab Callinectes sapidus in a patchy environment. Ecography 23: 21-31

Cooper SR, Brush GS (1993) A 2500 year history of anoxia and eutrophication in Chesapeake Bay. Estuaries 16:617-626

Das T, Stickle WB (1993) Sensitivity of crabs Callinectes sapidus and C. similis and the gastropod Stramonita haemastoma to hypoxia and anoxia. Mar Ecol Prog Ser 98:263-274

Das T, Stickle WB (1994) Detection and avoidance of hypoxic water by juvenile Callinectes sapidus and C. similis. Mar Biol 120:593-600 
Diaz RJ, Rosenberg R (1995) Marine benthic hypoxia: a review of its ecological effects and the behavioural responses of benthic macrofauna. Oceanogr Mar Biol Annu Rev 33:245-303

Diaz RJ, Neubauer RJ, Schaffner LC, Pihl L, Baden SP (1992) Continuous monitoring of dissolved oxygen in an estuary experiencing periodic hypoxia and the effect of hypoxia on macrobenthos and fish. Sci Total Environ (Suppl) 1992: $1055-1068$

Eby L (2001) Response of a fish community to frequent and infrequent disturbances in an estuarine ecosystem. PhD dissertation, Duke University, Durham, NC

Eby LA, Crowder LB (2002) Hypoxia-based habitat compression in the Neuse River Estuary: context-dependent shifts in behavioral avoidance thresholds. Can J Fish Aquat Sci 59:952-965

Eggleston DB, Lipcius RN, Hines AH (1992) Density-dependent predation by blue crabs upon infaunal clam species with contrasting distribution and abundance patterns. Mar Ecol Prog Ser 85:55-68

Hines AH, Comtois KL (1985) Vertical distribution of infauna in sediments of a subestuary of central Chesapeake Bay. Estuaries 8:296-304

Hines AH, Haddon AM, Wiechert LA (1990) Guild structure and foraging impact of blue crabs and epibenthic fish in a subestuary of Chesapeake Bay. Mar Ecol Prog Ser 67: $105-126$

Judy MH, Dudley DL (1970) Movements of Tagged Blue Crabs in North Carolina Waters. Comm Fish Rev 32:29-35

Laughlin RA (1982) Feeding habits of the blue crab, Callinectes sapidus Rathbun, in the Apalachicola estuary, Florida. Bull Mar Sci 32:807-822

Lipcius RN, Hines AH (1986) Variable functional responses of a marine predator in dissimilar homogeneous microhabitats. Ecology 67:1361-1371

Lowery TA, Tate LG (1986) Effect of hypoxia on hemolymph lactate and behavior of the blue crab Callinectes sapidus Rathbun in the laboratory and field. Comp Biochem Physiol 85A:689-692

Luettich RA Jr, McNinch JE, Paerl HW, Peterson $\mathrm{CH}$, Wells JT, Alperin M, Martens CS, Pinckney JL (2000) Neuse River Estuary modeling and monitoring project stage 1: hydrography and circulation, water column nutrients and productivity, sedimentary processes and benthic-pelagic coupling, and benthic ecology. Report No. 325-B, Water Resources Research Institute of the University of North Carolina

Mangum CP (1997) Adaptation of the oxygen transport system to hypoxia in the blue crab, Callinectes sapidus. Am Zool 37:604-611

Mansour RA, Lipcius RN (1991) Density-dependent foraging

Editorial responsibility: Otto Kinne (Editor),

Oldendorf/Luhe, Germany and mutual interference in blue crabs preying upon infaunal clams. Mar Ecol Prog Ser 72:239-246

McClellan CM (2001) Mesoscale habitat use of juvenile southern flounder, Paralichthys lethostigma: responses to environmental variability. MS thesis, Duke University, Durham, NC

Nye LA (1989) Variation in feeding behavior of blue crabs (Callinectes sapidus Rathbun) measured by ultrasonic biotelemetry. MS thesis, North Carolina State University, Raleigh, NC

Officer CB, Biggs RB, Taft JL, Cronin LE, Tyler MA, Boynton WR (1984) Chesapeake Bay anoxia: origin, development, and significance. Science 223:22-27

Pihl L, Baden SP, Diaz RJ (1991) Effects of periodic hypoxia on distribution of demersal fish and crustaceans. Mar Biol 108:349-360

Pihl L, Baden SP, Diaz RJ, Schaffner LC (1992) Hypoxiainduced structural changes in the diet of bottom-feeding fish and crustacea. Mar Biol 112:349-361

Sanford LP, Sellner KG, Breitburg DL (1990) Covariability of dissolved oxygen with physical processes in the summertime Chesapeake Bay. J Mar Res 48:567-590

Seitz RD, Lipcius RN (2001) Variation in top-down and bottom-up control of marine bivalves at differing spatial scales. ICES J Mar Sci 58:689-699

Seitz RD, Lipcius RN, Hines AH, Eggleston DB (2001) Density-dependent predation, habitat variation, and the persistence of marine bivalve prey. Ecology 82:2435-2451

Stanley DW, Nixon SW (1992) Stratification and bottom-water hypoxia in the Pamlico River estuary. Estuaries 15: $270-281$

Tallqvist M (2001) Burrowing behaviour of the Baltic clam Macoma balthica: effects of sediment type, hypoxia and predator presence. Mar Ecol Prog Ser 212:183-191

Taylor DL, Eggleston DB (2000) Effects of hypoxia on an estuarine predator-prey interaction: foraging behavior and mutual interference in the blue crab Callinectes sapidus and the infaunal clam prey Mya arenaria. Mar Ecol Prog Ser 196:221-237

Weissburg MJ, Zimmerfaust RK (1993) Life and death in moving fluids: hydrodynamic effects on chemosensory-mediated predation. Ecology 74:1428-1443

Wolcott TG, Hines AH (1989) Ultrasonic biotelemetry of muscle activity from free-ranging marine animals: a new method for studying foraging by blue crabs (Callinectes sapidus). Biol Bull (Woods Hole) 176:50-56

Wolcott TG, Hines AH (1990) Ultrasonic telemetry of smallscale movements and microhabitat selection by molting blue crabs (Callinectes sapidus). Bull Mar Sci 46:83-94

Zar JH (1984) Biostatistical analysis. Prentice Hall, Englewood Cliffs, NJ

Submitted: October 21, 2002; Accepted: August 5, 2003

Proofs received from author(s): August 26, 2003 